\title{
Therapeutic efficacy of azathioprine in addition to prednisone-based regimens as first-line chronic graft-versus-host disease treatment
}

\author{
Jieun Uhm ${ }^{1,2}$ - Elizabeth Shin ${ }^{3}$. Fotios V. Michelis ${ }^{1}$ Santhosh Thyagu ${ }^{1}$ - Auro Viswabandya ${ }^{1} \cdot$ Jeffrey H. Lipton ${ }^{1}$. \\ Hans A. Messner ${ }^{1} \cdot$ Dennis (Dong hwan) Kim ${ }^{1}$
}

Received: 30 May 2016 / Revised: 7 August 2017 / Accepted: 20 September 2017 / Published online: 15 December 2017

(c) The Author(s) 2018. This article is published with open access

Chronic graft-versus-host disease (cGVHD) is a major complication of allogeneic hematopoietic stem cell transplantation (allo-HCT) that is related to higher mortality and morbidity [1,2]. Glucocorticoids has been the mainstay of the treatment for cGVHD, while it also has been widely used to treat the variety of autoimmune diseases as the combination with other immunosuppressive agents including azathioprine (AZP) to reduce long-term complications of glucocorticoids such as diabetes mellitus, iatrogenic Cushing's syndrome, avascular necrosis of joints and osteoporosis, etc. [3-6].

Although a previous clinical trial suggested that prednisone (PRD) based regimen plus AZP (PRD + AZP) resulted in worse survival than PRD-based regimen in a standard risk group of cGVHD patients due to higher nonrelapse (infection-related) mortality (NRM) [7], the therapeutic efficacy of AZP might deserve to be looked at again because there have been advances in the allo-HCT field for over the last decades, including significant improvement in supportive care such as infectious prophylaxis and treatment, as well as in evaluating cGVHD systematically. The National Institutes of Health (NIH) first proposed consensus criteria for the diagnosis of cGVHD, and tools for scoring cGVHD organ involvement and assessing overall severity in 2005, which are now widely used in clinical practice $[8,9]$. In addition, a new statistical endpoint for evaluating the efficacy of cGVHD treatment, i.e. failure free survival

Dennis (Dong hwan) Kim

dr.dennis.kim@uhn.ca

1 Allogeneic Blood And Marrow Transplant Program, Division of Medical Oncology and Hematology, Princess Margaret Cancer Centre, Department of Medicine, University of Toronto, 610 University Ave. Toronto, Ontario, Canada M5G2M9

2 Hematology and Oncology, Department of Internal Medicine, Hanyang University Seoul Hospital, College of Medicine, Hanyang University, Seoul, Korea

3 School of Medicine, University of Toronto, Toronto, Canada
(FFS), has been introduced and suggested to be a potential surrogate of overall survival (OS) for cGVHD treatment $[10,11]$. Therefore, we retrospectively reviewed 668 consecutive patients who underwent allo-HCT between 2004 and 2012 at Princess Margaret Cancer Centre, Toronto, Canada in order to compare the efficacy of PRD + AZP and PRD-based regimens with respect to FFS as well as OS, NRM, and the incidence of relapse.

Chronic GVHD was defined, reclassified and graded by the NIH consensus criteria [8]. Among 313 patients with redefined cGVHD, we then identified 240 patients who received PRD or PRD + AZP as first line treatment for cGVHD. Late onset acute GVHD was excluded from the analysis.

The FFS was defined as time from the initiation of frontline treatment for cGVHD to treatment failure (TF), NRM or relapse of disease. TF was defined as initiation of the next line of IST for cGVHD [11] or an escalation of the dose of PRD to $\geq 1 \mathrm{mg} / \mathrm{kg} / \mathrm{day}$ regardless of the target organ. OS and FFS were calculated by the Kaplan-Meier method and compared using the log rank test. The cumulative incidences of NRM, disease relapse, and the TF rate (TFR) for front line cGVHD treatment were estimated considering competing risks, with disease relapse, NRM and TFR considered as mutually-competing risks.

The transplant-related characteristics were analyzed to compare the PRD and PRD + AZP groups using Pearson's $\mathrm{X}^{2}$ or Fisher's exact test. The univariate and multivariate analyses performed to compare OS, NRM, relapse incidence, and FFS between two treatment groups. OS and FFS were compared using the $\log$ rank test. Univariate analyses for incidence with competing risks were performed by Gray's method. Cox proportional hazard regression model was used for multivariate analysis of survivals.

Since the characteristics of cGVHD of two treatment groups were imbalanced (Table 1), we performed a propensity score matching (PSM) analysis as a case-control study in order to adjust the potential confounding effects of the clinical features of cGVHD on treatment outcome. The 
Table 1 Characteristics of patients and chronic GVHD

\begin{tabular}{|c|c|c|c|c|c|c|c|c|}
\hline & \multicolumn{4}{|l|}{ Whole cohort } & \multicolumn{4}{|c|}{ Propensity score matching analysis cohort } \\
\hline & $\begin{array}{l}\text { All } \\
(\%, n=240)\end{array}$ & $\begin{array}{l}\text { Prednisone } \\
\text { alone } \\
(\%, n=142)\end{array}$ & $\begin{array}{l}\text { Prednisone and } \\
\text { Azathioprine } \\
(\%, n=98)\end{array}$ & $p$-value & $\begin{array}{l}\text { All } \\
(\%, n=148)\end{array}$ & $\begin{array}{l}\text { Prednisone } \\
\text { alone } \\
(\%, n=74)\end{array}$ & $\begin{array}{l}\text { Prednisone and } \\
\text { Azathioprine } \\
(\%, n=74)\end{array}$ & $p$-value \\
\hline $\begin{array}{l}\text { Median age at transplant, } \\
\text { year (range) }\end{array}$ & $50(19-70)$ & $50(19-68)$ & $51(19-70)$ & & $52(20-70)$ & $52(21-69)$ & $52(20-70)$ & \\
\hline \multicolumn{9}{|l|}{ Gender, no. (\%) } \\
\hline Male & $137(57.1)$ & $79(55.6)$ & $58(59.2)$ & \multirow[t]{2}{*}{0.598} & $83(56)$ & $41(55)$ & $42(57)$ & \multirow[t]{2}{*}{0.868} \\
\hline Female & $103(42.9)$ & $63(44.4)$ & $40(40.8)$ & & $65(44)$ & $33(46)$ & $32(43)$ & \\
\hline \multicolumn{9}{|l|}{ Gender mismatch, no. $(\%)$} \\
\hline Female to male & $53(22.1)$ & $31(21.8)$ & $22(22.4)$ & \multirow[t]{2}{*}{1.000} & $31(21)$ & $14(19)$ & $17(23)$ & \multirow[t]{2}{*}{0.545} \\
\hline Other & $187(77.9)$ & $111(78.2)$ & $76(77.6)$ & & $117(79)$ & $60(81)$ & $57(77)$ & \\
\hline \multicolumn{9}{|l|}{ Disease, no. (\%) } \\
\hline AML & $104(43.3)$ & $60(42.3)$ & $44(44.9)$ & \multirow[t]{9}{*}{0.760} & $64(43)$ & $33(45)$ & $31(42)$ & \multirow[t]{9}{*}{0.791} \\
\hline ALL & $22(9.1)$ & $11(7.7)$ & $11(11.2)$ & & $13(9)$ & $8(11)$ & $5(7)$ & \\
\hline MDS & $23(9.6)$ & $13(9.2)$ & $10(10.2)$ & & $16(11)$ & $7(10)$ & $9(12)$ & \\
\hline CML & $17(7.1)$ & $13(9.2)$ & $4(4.1)$ & & $9(6)$ & $6(8)$ & $3(4)$ & \\
\hline CLL & $21(8.8)$ & $14(9.9)$ & $7(7.1)$ & & $14(10)$ & $7(10)$ & $7(10)$ & \\
\hline MF/MPD & $21(8.7)$ & $12(8.5)$ & $9(9.2)$ & & $11(7)$ & $4(5)$ & $7(10)$ & \\
\hline Malignant lymphoma & $27(11.3)$ & 15 (10.6) & $12(12.2)$ & & $20(14)$ & $9(12)$ & $11(15)$ & \\
\hline AA & $4(1.7)$ & $3(2.1)$ & $1(1.0)$ & & $1(1)$ & $0(0)$ & $1(1)$ & \\
\hline MM & $1(0.4)$ & $1(0.7)$ & $0(0)$ & & $0(0)$ & $0(0)$ & $0(0)$ & \\
\hline \multicolumn{9}{|c|}{ Intensity of conditioning regimen, no. (\%) } \\
\hline Myeloablative & $154(64.2)$ & $93(65.5)$ & $61(62.2)$ & \multirow[t]{2}{*}{0.681} & $90(61)$ & $47(64)$ & $43(58)$ & \multirow[t]{2}{*}{0.501} \\
\hline Non-myeloablative & $86(35.8)$ & $49(34.5)$ & $37(37.8)$ & & $58(39)$ & $27(37)$ & $31(42)$ & \\
\hline \multicolumn{9}{|l|}{ HLA and donor type, no. (\%) } \\
\hline Related & $146(60.8)$ & $84(59.1)$ & $62(62.2)$ & \multirow[t]{3}{*}{0.489} & $96(65)$ & $46(62)$ & $50(68)$ & \multirow[t]{3}{*}{0.591} \\
\hline Unrelated & $86(35.8)$ & $54(38)$ & $32(32.7$ & & $46(31)$ & $25(34)$ & $21(28)$ & \\
\hline Missing & $8(3.3)$ & $4(2.8)$ & $4(4.1)$ & & $6(4)$ & $3(4)$ & $3(4)$ & \\
\hline \multicolumn{9}{|l|}{ Stem cell source, no. $(\%)$} \\
\hline Bone marrow & $19(7.9)$ & $12(8.5)$ & $7(7.1)$ & \multirow[t]{2}{*}{0.811} & $8(5)$ & $4(5)$ & $4(5)$ & \multirow[t]{2}{*}{1} \\
\hline Peripheral blood & $221(92.1)$ & $130(91.5)$ & $91(92.9)$ & & $140(95)$ & $70(95)$ & $70(95)$ & \\
\hline T-cell depletion, no. (\%) & $46(19.2)$ & $33(23.2)$ & $13(13.3)$ & 0.054 & $24(16)$ & $16(22)$ & $8(11)$ & 0.074 \\
\hline Any grade of acute GVHD & $181(78.9)$ & $113(81.9)$ & $68(73.9)$ & 0.148 & $106(72)$ & $57(77)$ & $49(66)$ & 0.149 \\
\hline $\begin{array}{l}\text { Median onset of cGVHD, } \\
\text { Day }(95 \% \mathrm{CI})\end{array}$ & $\begin{array}{l}140 \\
(131-149)\end{array}$ & $\begin{array}{l}132 \\
(123-141)\end{array}$ & $160(140-180)$ & $<0.001$ & $140(128-151)$ & $\begin{array}{l}140 \\
(130-149)\end{array}$ & $152(127-176)$ & 0.863 \\
\hline \multicolumn{9}{|c|}{ Classification of NIH cGVHD } \\
\hline Classical & $87(36.2)$ & $48(33.8)$ & $39(39.8)$ & \multirow[t]{2}{*}{0.418} & $51(34.5)$ & $26(35.1)$ & $25(33.8)$ & \multirow[t]{2}{*}{0.863} \\
\hline Overlap syndrome & $153(63.8)$ & $94(66.2)$ & $59(60.2)$ & & $97(65.5)$ & $48(64.9)$ & $49(65.5)$ & \\
\hline Global score of cGVHD at & treatment & & & & & & & \\
\hline Mild & $24(10.0)$ & $16(11.3)$ & $8(8.2)$ & $<0.001$ & $14(9.5)$ & $6(8.1)$ & $8(10.8)$ & 0.319 \\
\hline Moderate & $173(72.1)$ & $89(62.7)$ & $84(85.7)$ & & $122(82.5)$ & $59(79.7)$ & $62(83.8)$ & \\
\hline Severe & $43(17.9)$ & $37(26.1)$ & $6(6.1)$ & & $12(8.1)$ & $9(12.2)$ & $4(5.4)$ & \\
\hline Organs involved in cGVHD & & & & & & & & \\
\hline Skin & 155 (64.6) & $88(62.0)$ & $67(68.4)$ & 0.108 & $101(68)$ & $54(73)$ & $47(64)$ & 0.219 \\
\hline Mouth & $116(48.3)$ & $66(46.5)$ & $50(51.0)$ & 0.359 & $72(49)$ & $33(45)$ & $39(53)$ & 0.341 \\
\hline Eyes & $77(32.1)$ & $45(31.7)$ & $32(32.7)$ & 0.889 & $46(31)$ & $21(28)$ & $25(34)$ & 0.477 \\
\hline Gastrointestinal tract & $50(20.8)$ & $36(25.4)$ & $14(14.3)$ & 0.052 & $22(15)$ & $12(16)$ & $10(14)$ & 0.644 \\
\hline
\end{tabular}


Table 1 (continued)

\begin{tabular}{|c|c|c|c|c|c|c|c|c|}
\hline & \multicolumn{4}{|l|}{ Whole cohort } & \multicolumn{4}{|c|}{ Propensity score matching analysis cohort } \\
\hline & $\begin{array}{l}\text { All } \\
(\%, n=240)\end{array}$ & $\begin{array}{l}\text { Prednisone } \\
\text { alone } \\
(\%, n=142)\end{array}$ & $\begin{array}{l}\text { Prednisone and } \\
\text { Azathioprine } \\
(\%, n=98)\end{array}$ & $p$-value & $\begin{array}{l}\text { All } \\
(\%, n=148)\end{array}$ & $\begin{array}{l}\text { Prednisone } \\
\text { alone } \\
(\%, n=74)\end{array}$ & $\begin{array}{l}\text { Prednisone and } \\
\text { Azathioprine } \\
(\%, n=74)\end{array}$ & $p$-value \\
\hline Liver & $166(69.2)$ & $94(66.2)$ & $72(73.5)$ & 0.202 & $109(74)$ & $55(74)$ & $54(73)$ & 0.604 \\
\hline Lung & $21(8.8)$ & $18(12.7)$ & $3(3.1)$ & 0.010 & $5(3)$ & $2(3)$ & $3(4)$ & 0.649 \\
\hline Musculoskeletal system & $13(5.4)$ & $6(4.2)$ & $7(7.1)$ & 0.326 & $7(5)$ & $4(5)$ & $3(4)$ & 0.699 \\
\hline Others & $7(2.9)$ & $4(2.8)$ & $3(3.1)$ & 0.912 & $5(3)$ & $3(4)$ & $2(3)$ & 0.649 \\
\hline \multicolumn{9}{|l|}{ No. of organs involved } \\
\hline $1-2$ & $122(50.8)$ & $76(53.5)$ & $46(46.9)$ & 0.523 & $79(53.4)$ & $41(55.4)$ & $38(51.4)$ & 0.789 \\
\hline 3 & $74(30.8)$ & $40(28.2)$ & $34(34.7)$ & & $44(20.7)$ & $22(29.7)$ & $22(29.7)$ & \\
\hline 4 or more & $44(18.3)$ & $26(18.3)$ & $18(18.4)$ & & 25 (16.9) & $1(14.9)$ & $14(18.9)$ & \\
\hline Progressive type onset & $25(10.5)$ & $22(15.5)$ & $3(3.1)$ & 0.002 & $7(4.7)$ & $4(5.4)$ & $3(4.1)$ & 1 \\
\hline $\begin{array}{l}\text { Extensive skin } \\
\text { involvement }\end{array}$ & $84(35.4)$ & $51(35.9)$ & $33(34.7)$ & 0.468 & $59(41)$ & $31(42)$ & $28(39)$ & 0.576 \\
\hline \multicolumn{9}{|l|}{ ECOG performance status } \\
\hline $0-1$ & $185(77.1)$ & $101(71.1)$ & $84(85.7)$ & 0.008 & $129(87.2)$ & $65(87.8)$ & $64(86.5)$ & 0.806 \\
\hline 2 or higher & $55(22.9)$ & $41(28.9)$ & $14(14.2)$ & & $19(12.8)$ & $9(12.2)$ & $10(13.5)$ & \\
\hline Thrombocytopenia & $67(27.9)$ & $49(34.5)$ & $18(18.4)$ & 0.008 & $34(23.0)$ & $18(24.3)$ & $16(21.6)$ & 0.696 \\
\hline Eosinophilia & $86(35.8)$ & $49(34.5)$ & $18(18.4)$ & 0.020 & $62(42)$ & $31(42)$ & $31(42)$ & 1.000 \\
\hline Lymphopenia & $153(64.0)$ & $98(68.5)$ & $55(56.1)$ & 0.021 & $89(61)$ & $45(62)$ & $44(60)$ & 0.613 \\
\hline $\begin{array}{l}\text { Calcineurin inhibitors in } \\
\text { addition to PRD or PRD }+ \\
\text { AZP }\end{array}$ & $149(62.1)$ & 99 (69.7) & $50(56.1)$ & 0.003 & 87 (58.8) & $45(60.8)$ & $42(56.8)$ & 0.616 \\
\hline
\end{tabular}

$A M L$ acute myeloid leukemia, $A L L$ acute lymphoblastic leukemia, $M D S$ myelodysplastic syndrome, $C M L$ chronic myelogenous leukemia, $M F$ myelofibrosis, $M P D$ myeloproliferative disorder, $C L L$ chronic lymphocytic leukemia, $A A$ aplastic anemia, $M M$ multiple myeloma, $H L A$ human leukocyte antigen, GVHD graft-versus-host disease, $c G V H D$ chronic GVHD, 95\% CI 95\% confidence interval

clinical variables included in the propensity score calculations were global score (GS) by the NIH consensus criteria, the classification of the cGVHD (classical or overlap syndrome), age, gender, duration from allo-HCT to initiation of cGVHD treatment, performance status (PS), progressive type onset (PTO) of cGVHD, thrombocytopenia and organs involved cGVHD per skin, gastrointestinal track, liver, lung, and musculoskeletal system. A total of 74 case-control pairs were identified with $<0.1$ of a difference in propensity score.

Of the 240 patients included in the analysis, 154 (64.2\%) received myeloablative conditioning (MAC) and 86 $(35.8 \%)$ reduced-intensity conditioning (RIC) (Table 1). There were no significant differences in pretransplant characteristics between the PRD and PRD + AZP groups except for T-cell depletion (TCD); 33 patients $(23.2 \%)$ in the PRD group and $13(13.3 \%)$ in the PRD + AZP group underwent $\mathrm{T}$-cell depletion $(p=0.054)$. The imbalanced characteristics of cGVHD were observed between the 2 groups, including longer duration from HCT to diagnosis of cGVHD $(p<0.001)$ in the PRD + AZP group; also fewer patients with severe cGVHD $(p<0.001)$, fewer with PTO $(p=0.002)$, fewer with thrombocytopenia $(p=0.008)$ and better PS $(p=0.008)$.

With a follow-up duration of 43.6 months among survivors, 2-year FFS, TFR, NRM, and relapse incidence were $24.7 \%$ (95\% confidence interval (CI), 19.1-30.8\%), $57.5 \%$ (50.8-64.0\%), 7.5\% (4.5-11.5\%), and 10.1\% (6.5-14.5\%), respectively. The PRD + AZP group had a higher FFS rate at 2 years $(36.4 \%$ [26.2-46.6\%]) than the PRD group (16.8\% [10.8-23.9\%], $p<0.001$ ) (Fig. 1a) and a lower incidence of TFR at 2 years (52\% [40.8-62.0\%] versus $61.5 \%$ [52.5-69.3\%], $p=0.050)$. In addition, it had a lower NRM rate at 2 years $(3.4 \%$ [0.9-8.85] versus $10.5 \%$ $[6-16.5 \%], p=0.050)$. There was no difference between the groups in the cumulative incidence of relapse at 2 years; $8.3 \%(3.6-15.5 \%, p=0.507)$ in PRD + AZP group and $11.3 \%(6.5-17.4 \%)$ in PRD group.

Severity by the NIH consensus criteria was wellcorrelated with FFS. The FFS rate at 2 years was $62.2 \%$ (39.9-78.3\%) in mild, $20.5 \%(14.2-27.7 \%)$ in moderate, and $16.9 \%(7.5-29.6 \%)$ in severe cGVHD $(p<0.001)$. Patients with mild cGVHD had a lower TFR $(29.2 \%$ [12.6-48.1\%]) at 2 years than those with moderate/severe cGVHD $(61.4 \%$ [54-68\%], $p=0.008)$. Severity by the 


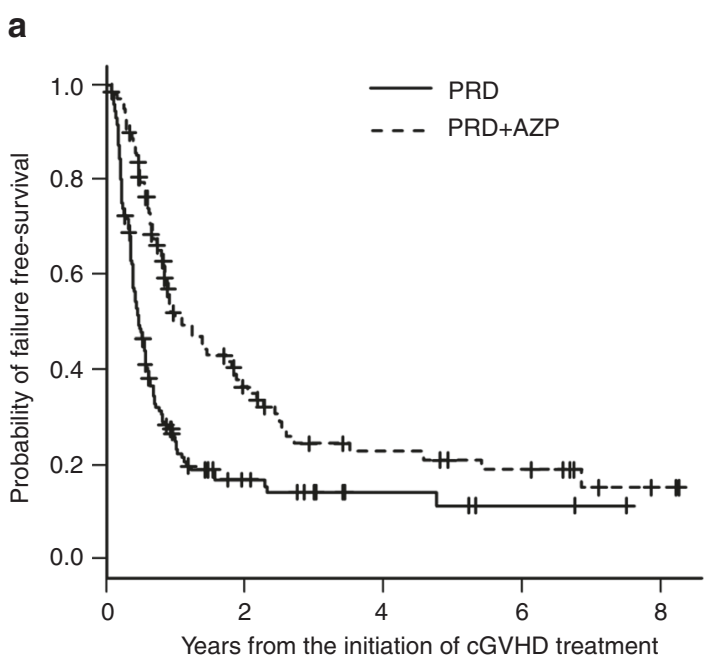

Fig. 1 Survivals and the treatment failure $(n=240)$. a Failure-free survival comparing the prednisone and prednisone/azathioprine groups. b Adjusted overall survival comparing the prednisone and

NIH consensus criteria does not correlate with the cumulative incidence of NRM $(p=0.538)$ or relapse ( $p=$ 0.826). None of the factors associated with FFS or cumulative incidences of TFR and NRM were correlated with relapse rate.

OS at 2 years was $71.6 \%(64.6-77.4 \%)$; PRD + AZP group showed better survival compared to the PRD group (OS at 2 years; $82.1 \%$ [71-89.2\%] versus $64.8 \%$ [55.4-72.8\%], $p<0.001)$. And the severities of cGVHD and PS correlated well with 2-year OS $(p=0.004$ and $p<$ 0.001 , respectively). The adjusted OS for PRD and PRD + AZP groups demonstrated statistical significance considering the severities of cGVHD and PS (HR for PRD group 2.09 [1.22-3.58], $p=0.007$ ) (Fig. 1b).

Univariate analysis for FFS identified several risk factors associated with worse FFS including moderate/severe cGVHD (median FFS (months); 55.9 versus 7.6, $p=$ 0.001 ), ECOG PS $\geq 2$ (9 versus $5.4, p=0.003$ ), thrombocytopenia (6.5 versus $6.2, p=0.05$ ), PTO (8.6 versus 2.7 , $p=0.001$ ), and PRD group (13.2 versus 5.6, $p<0.001$ ). Multivariate analysis confirmed that moderate/severe cGVHD (hazard ratio [HR] 3.10, $p<0.001$ ), PTO (HR $2.21, p=0.001)$ and PRD (versus PRD + AZP) as the firstline treatment regimen (HR 2.12, $p<0.001$ ) were risk factors for worse FFS.

After PSM, the characteristics of cGVHD were wellbalanced in the two groups (Table 1). The PSM analysis confirmed the findings of superior outcomes in the PRD + AZP group. Two-year FFS was significantly better in the PRD + AZP (36.4\%) than the PRD group $(16.8 \%, p<$ $0.001)$. The cumulative incidence of TFR for frontline treatment at 2 years was also lower in the PRD + AZP group $(52.4 \%$ versus $70.1 \%, p=0.013)$. There were no

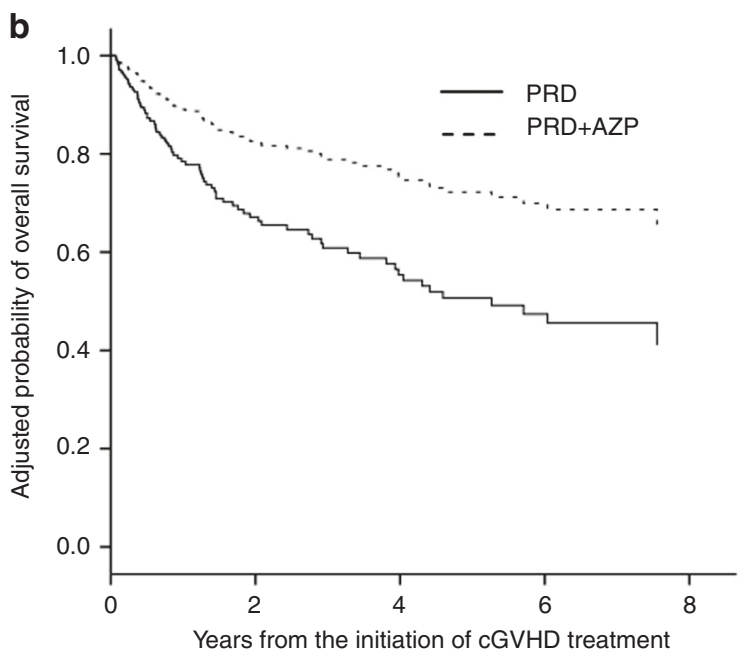

prednisone/azathioprine groups considering the severities of chronic graft-versus-host disease and performance status

significant differences in NRM or relapse rate at 2 years, but a trend towards longer OS was again observed in the PRD + AZP group of the PSM cohort (85.3\% [72.6-92.4\%] at 2 years in PRD + AZA group versus $75.9 \%$ [63.1-84.8\%] in PRD group, $p=0.066$ ).

When confined to the same severity level according to the NIH consensus criteria, there was also a trend towards longer FFS in the PRD + AZP group: the favorable effect of $\mathrm{PRD}+\mathrm{AZP}$ was statistically significant in the subgroup with moderate grade of cGVHD [FFS at 2 years (\%); 30.5 versus $9.1, p=0.001$ ], but not in the mild and severe grades. Similar results were obtained for the cumulative incidence of TFR of frontline treatment at 2 years among the patients with moderate cGVHD; 56.2\% (41.6-68.6\%) in the PRD + AZP group and 71.4\% (46.8-81.7\%) in the PRD group $(p=0.035)$.

In addition, it was found that tapering of PRD dose $<0.5$ $\mathrm{mg} / \mathrm{kg} /$ day was more successful in the PRD + AZP group than in the PRD group: the cumulative incidence of PRD < $0.5 \mathrm{mg} / \mathrm{kg} / \mathrm{day}$ at 6 months was $90.5 \%$ in the PRD + AZP group and $75.8 \%$ in PRD group $(p=0.018)$.

Although PSM analysis performed to overcome and control the imbalance of patients' characteristics between PRD and PRD + AZP groups, the results of this study should be interpreted with caution given the nature of the retrospective analysis of this study, which would be weak evidence to support the role of AZP in cGVHD treatment compared the previous trial [7]. However, AZP added to a PRD-based regimen as the first-line treatment for cGVHD seems to improve FFS and may have a role as a steroidsparing agent in the modern allo-HCT era. Since two thirds of the patients who required PRD-based treatment for cGVHD experienced the TF at 2 years, a better treatment 
strategy would be required. AZP could be worth reconsidered as a relevant option for a steroid sparing agent in cGVHD treatment.

Acknowledgements This study was presented in abstract form at the 56th annual meeting of the American Society of Hematology, Orlando, FL, December 6, 2015. Abstract 3126.

\section{Compliance with ethical standards}

Conflict of interest The authors declare that they have no competing interests.

Open Access This article is licensed under a Creative Commons Attribution 4.0 International License, which permits use, sharing, adaptation, distribution and reproduction in any medium or format, as long as you give appropriate credit to the original author(s) and the source, provide a link to the Creative Commons license, and indicate if changes were made. The images or other third party material in this article are included in the article's Creative Commons license, unless indicated otherwise in a credit line to the material. If material is not included in the article's Creative Commons license and your intended use is not permitted by statutory regulation or exceeds the permitted use, you will need to obtain permission directly from the copyright holder. To view a copy of this license, visit http://creativecommons. org/licenses/by/4.0/.

\section{References}

1. Lee SJ, Klein JP, Barrett AJ, Ringden O, Antin JH, Cahn JY, et al. Severity of chronic graft-versus-host disease: association with treatment-related mortality and relapse. Blood. 2002;100:406-14.

2. Sutherland HJ, Fyles GM, Adams G, Hao Y, Lipton JH, Minden $\mathrm{MD}$, et al. Quality of life following bone marrow transplantation: a comparison of patient reports with population norms. Bone Marrow Transplant. 1997;19:1129-36. https://doi.org/10.1038/sj. bmt.1700806.
3. Choy EH, Isenberg DA. Treatment of dermatomyositis and polymyositis. Rheumatology. 2002;41:7-13.

4. Hahn BH, McMahon MA, Wilkinson A, Wallace WD, Daikh DI, Fitzgerald JD, et al. American College of Rheumatology guidelines for screening, treatment, and management of lupus nephritis. Arthritis Care Res. 2012;64:797-808. https://doi.org/10.1002/acr. 21664.

5. Kirk AP, Lennard-Jones JE. Controlled trial of azathioprine in chronic ulcerative colitis. Br Med J. (Clin ResEd) 1982; 284:1291-2.

6. Meriggioli MN, Sanders DB. Autoimmune myasthenia gravis: emerging clinical and biological heterogeneity. Lancet Neurol. 2009;8:475-90. https://doi.org/10.1016/S1474-4422(09) 70063-8.

7. Sullivan KM, Witherspoon RP, Storb R, Weiden P, Flournoy N, Dahlberg S, et al. Prednisone and azathioprine compared with prednisone and placebo for treatment of chronic graft-v-host disease: prognostic influence of prolonged thrombocytopenia after allogeneic marrow transplantation. Blood. 1988;72:546-54.

8. Filipovich AH, Weisdorf D, Pavletic S, Socie G, Wingard JR, Lee SJ, et al. National Institutes of Health consensus development project on criteria for clinical trials in chronic graft-versus-host disease: I. Diagnosis and staging working group report. Biol Blood Marrow Transplant. 2005;11:945-56. https://doi.org/10. 1016/j.bbmt.2005.09.004.

9. Jagasia MH, Greinix HT, Arora M, Williams KM, Wolff D, Cowen EW, et al. National Institutes of Health Consensus Development Project on Criteria for Clinical Trials in Chronic Graft-versus-Host Disease: I. The 2014 Diagnosis and Staging Working Group report. Biol Blood Marrow Transplant. 2015;21:389-401. https://doi.org/10.1016/j.bbmt.2014.12.001.

10. Inamoto Y, Flowers ME, Sandmaier BM, Aki SZ, Carpenter PA, Lee SJ, et al. Failure-free survival after initial systemic treatment of chronic graft-versus-host disease. Blood. 2014;124:1363-71. https://doi.org/10.1182/blood-2014-03-563544.

11. Inamoto Y, Storer BE, Lee SJ, Carpenter PA, Sandmaier BM, Flowers $\mathrm{ME}$, et al. Failure-free survival after second-line systemic treatment of chronic graft-versus-host disease. Blood. 2013;121:2340-6. https://doi.org/10.1182/blood-2012-11465583. 